\title{
ISLAM WASTHIYYAH DALAM KACA MATA TAFSIR
}

\section{AL-QUR'AN}

(Kajian Teks, Konteks, dan Kontekstualisasi Penafsiran Dalam Q.S. Al-Baqarah: 143)

\section{Arif Sugitanata}

Universitas Islam Negeri Sunan Kalijaga Yogyakarta

Email: arifsugitanata@yahoo.co.id

\section{Nena Septiana Bakti}

Universitas Islam Negeri UIN Mataram

Email: neozseptiana77@gmail.com

\section{Abstract}

This paper discusses the concept of Wasthiyyah Islam in the perspective of the Qur'an through various interpretations. Specifically, there are several aspects that became the focal point of this study. First, looking back at the concept of Islamic Wasathiyyah in the Qur'an. Second, revealing the context and nature of Islam Wasathiyyah in a variety of interpretations. Third, to actualize the characteristics of Wasathiyyah Islam in the current context. The research approach used is the study literature approach which is based on several references that support related books, journals, articles and so on. The results of this study indicate that the concept of Islamic Wasathiyyah in terms of several interpretive perspectives can be said as a sociological concept of Islam that emphasizes aspects universally related to the context of harmonious religious life, tolerance, and forming a moderate Islam in order to eliminate the extreme attitudes that have been many addressed to Islam.

Tulisan ini mencoba untuk mendiskusikan konsep Islam Wasthiyyah dalam perspektif Al-Qur'an melalui berbagai ragam Tafsir. Secara spesifik ada beberapa aspek yang menjadi titik fokus penelitian ini yaitu, Pertama, melihat kembali konsep Islam Wasthiyyah dalam Al-Qur'an. Kedua, mengungkapkan konteks dan hakikat Islam Wasthiyyah dalam 
192 Rausyan Fikr, Vol. 16 No. 1 Juni 2020: 191 - 211 .

ragam tafsir. Ketiga, mengaktualisasikan karakteristik Islam Wasthiyyah dalam konteks kekinian saat ini. Adapun pendekatan penelitian yang digunakan adalah pendekatan study literature yang didasarkan pada beberapa refrensi yang mendukung terkait buku, jurnal, artikel dan sebagainya. Hasil penelitian ini menunjukkan bahwa konsep Islam Wasathiyyah ditinjau dari beberapa perspektif tafsir dapat dikatakan sebagai konsep Islam secara sosiologis yang menekankan pada aspek secara universal kaitanya dengan konteks kehidupan beragama yang harmonis, toleransi, dan membentuk Islam yang moderat demi menghilangkan sikap yang ekstrim yang selama ini banyak ditujukan kepada Islam.

\section{Kata kunci: Kontekstualisasi, Islam Wasathiyyah, Al-Qur'an}

\section{PENDAHULUAN}

Isu tentang Islam selalu menjadi perbincangan yang tak pernah usai dalam perdebatan akademis. Selain itu, pemaknaan Islam secara sosiologis bermakna peyoratif, ada yang mengatakan, Islam sebagai agama yang liberal, ekstrim, progresif dan sebagainya. Sehingga secara psikologis, pemaknaan masyarakat tentang Islam terlampui secara luas dan memberikan variasi pengetahuan yang lebih produktif sehingga merubah presepsi secara kritis terhadap pemaknaan Islam sesungguhnya.

Emil Durkheim dalam Robert N. Bellah mendefinisikan secara sosiologis bahwa, agama sebagai sebuah bentuk keyakinan yang dianut umat manusia dan memiliki tata cara peribadatan yang dianggap suci dengan tujuan menyatukan seseorang dalam komunitas moral. ${ }^{1}$ Pendefinisian inipun berlaku pada konsep Islam Washtiyyah dalam konteks sosial-historis sebagai inspirasi lahirnya sebuah organisasi keagamaan.

${ }^{1}$ Robert N. Bellah, Religion in Human Evolution: From the Poleolithic to the Axial Age (Cambridge: The Belknap Press of Harvard University Press, 2011), h. 1. 
Ditinjau dari akar historisnya, Islam Pada hakikatnya memiliki sebuah konsep doktrin yang mengajarkan berbagai apsek kehidupan yang didalamnya memiliki banyak nilai secara universal untuk dikaji maknanya Islam sebagai (rahmatan lil allamin) yaitu sebagai agama Islam yang mengajarkan rahmat. Islam yang kian kini dijadikan sebagai ajaran yang sempurna. Namun pada kenyataanya selalu dikaji dan digali untuk menemukan sejatinya Islam yang sesungguhnya. Karena prinsip agama Islam adalah agama yang mengajarkan keterbukaan, terutama sekali dalam mengambil hikmah. ${ }^{2}$ Oleh karenanya, Islam meliputi berbagai kegiatan hidup manusia lebih bersifat komprehensif. Sebagai pemaknaannya, Islam bukan semata-mata dipengaruhi oleh politik melainkan hakikat Islam mencakup berbagai aspek kehidupan. ${ }^{3}$

Secara teologis, Islam adalah sistem nilai dan ajaran ilahiah, maka sifatnya transenden. Sepanjang perjalanan sejarahnya telah membantu para penganutnya untuk memahami realitas, yang pada giliranya mewujudkan pola pandang terhadap dunia (weltanschauung). Akan tetapi dari sudut sosiologis, ${ }^{4}$ Islam merupakan peradaban, kultur dan realitas sosial tidak sekedar sejumlah doktrin yang bersifat menzama, tetapi pada hakikatnya dia juga bersifat universal. Dapat dikatakan Islam berperan sebagai subyek yang turut menentukan perjalanan sejarah. ${ }^{5}$ Sangat wajar jika diantara para pemikiran sangat antusian dalam memahmai konsep

2 Jalaludin Rahmat, Islam Aktual, (Bandung: Mizan, Cet. X, 1998), h. 33

3 Hamka, Falsafah Hidup, "Memecahkan Rahasia Kehidupan Berdasarkan Al-Qur'an dan As-Sunnah”, (Jakarta: Republika Penerbit, 2015), h.343

${ }^{4}$ Jika ditelususri secara sisiologis bahwa, dimana Islam dipelajari misalnya dari sisi pengaruh agama terhadap masyarakat terhadap pemahaman Islam, penagruh pola interaksi soaial antar masyarakat Muslim terhadap ajaran Islam dan gerakan masyarakat mempengaruhi terhadap persepsi ajaran Islam. Baca selengkapnya, Kamaruzzaman Bustaman Ahmad, Islam Historis (Dinamika Studi Islam di Indonesia), (Yogyakarta: Galang Press, 2002).

${ }^{5}$ Supawi Pawenang, Islam Perspektif Manajemen, (Yogyakarta: Idea Prres, 2010), h. 28 
Islam yang sesungguhnya melalui beberapa perspektif untuk menemukan kebenaran agama Islam.

Berangkat dari problematika tersebut, Islam kian kini telah berkembang berbagai macam pemahaman agama. Salah satunya adalah yang dikenal dengan "trans-nasionalisme", yaitu pahampaham keagamaan dari luar. Paham-paham tersebut seringmengusik pemahaman agama mayoritas kaum muslimin, terutama merambah pada generasi muda yang masih minim pemahaman agamanya. Disebabkan doktrin keagamaan yang disikapi dengan kurang kritis dalam mengkaji suatu pemahaman konteks keagamaan yang berkembang. Munculnya kajian tafsir ${ }^{6}$ disebabkan karena menjelaskan dan mendalami makna-makna yang terkandung dalam ayat al-Qur'an secara lebih detali, baik dari segi himkah, pesan moral, hukum-hukumnya, maupun nilai-nilai etik universal yang ada didalamnya. Sehingga dalam menafsirkan ayat-ayat al-qur'an menggunakan berbagai macam metode-metode yang dipakai tentu semuat itu ingin mendapatkan hasil secara lebih terperinci dan global dalam suatu konteks yang ditafsirkan tersebut. ${ }^{7}$

Dengan demikian, kajian mengenai Ummatan Wasathan ini dianggap relevan pada masa kini, karena dalam perkembangan kini banyak pandangan-pandangan keagamaan yang berkembang di masyarakat yang mengarah pada sikap ekstrim, baik yang menuju pada fundamentalisme sempit dan kaku, maupun yang menuju pada

${ }^{6}$ Kajian Tafsir terkait dengan kandungan pemikiran dan metode berpikir yang mendasarinya dapat melahirkan dua aspek terhadap pemikiran para mufassir yaitu, kandungan penafsiran yang merupakan produk berpikir penafsir, dan metode penafsiran yang merupakan cara yang ditempuh penafsiran dalam menafsirkan AlQur'an, baik yang terkait dengan dengan bentukya seperti tafsir dengan riwayat dan tafsir dengan nalar, metodenya seperti tahlili, ijmali, dan mawdhu'i maupun corak lainya. Dalam perkembagan tafsir Al-Qur'an tentu saja berangkat dari perkembangan pemikiran tentang metodologi tafsir Al-Qur'an karena metodologi tafsirlah yang melahirkan produk penafsiran Nabi Muhammad Saw. yang disebut sebagai (al-tafsir al nabawi)

7 Abdul Mustaqim, Metode Penelitian Al-Qur'an dan Tafsir, (Yogyakarta: Idea Press, 2015), h. 12. 
pemahaman yang terlampau liberal dan kebablasan. Sehingga perlunya kajian ini untuk memberikan pemahaman secara signifikan dan mendalam bagaiamana Islam yang memberikan rasa aman, penyayang, dan toleransi antar sesama baik yang satu keyakinan maupun diluar keyakinan Agama Islam.

Kajian terhadap Islam pada kenyataannya lebih bersifat relativisme bahkan subjektivisme sehingga, pemahamana terhadap nilai-nilai Islam ditentukan oleh individu maupun kelompok. Hal ini dapat dibuktikan dengan melacak akar sejarah perkembangan dan perbedaan pemahaman Islam telah dimulai sejak zaman khawarij yang mewakili salah satu ujung ekstrimitas dalam Islam saat itu. Sehingga memahami Islam secara utuh tersebut terletak pada pemahaman atas aspek Syari'ah, Etika, dan terakhir pada konsep Jihad. $^{8}$

Dengan demikian, tulisan ini berusaha menguraikan konsep wasathiyah dalam Al-Qur'an dari sudut pandang ahli tafsir, untuk menemukan poin penting yang mampu meminimalisir 'misunderstanding' dan sikap intoleran yang rawan terjadi pada daerah-daerah tertentu akibat minimnya pemahaman umat tentang makna wasathiyah yang sebenarnya. Signifikansi akademik pembahasan ini akan sangat terasa khususnya pada saat ini apabila kita melihat ke arah positif dan mencari makna teks, konteks, dan kontekstualisasi dalam penafsiran al-Qur'an.

Lebih jauh lagi ayat tersebut perlu dikontekstualisasikan dalam konteks kekinian, karena dalam pencarian teks itu sangat penting "Nasr Hamid Abu Zaid" mengungkapkan untuk mendapatkan pengertian yang bisa menjelaskan tentang teks, Nashr hamid membedakan antara nass (teks) dan mushaf (buku). Menurutnya, nass (teks) berarti dalalah (makna) dan memerlukan pemahaman, penjelasan, dan interpretasi. Sedang mushaf (buku) tidaklah

${ }^{8}$ Jawhir Thontawi, Islam, Politik, dan Hukum Esai-esai Ilmiah untuk Pembaharuan" (Yogyakarta: Madyan Prres, 2002), h.3 
demikian, karena dia telah tertransformasikan menjadi sesuatu (syai'), baik itu berupa karya estetik, ataupun alat untuk mendapatkan berkah Tuhan. Kemudian teks menurut Abu Zayd terbagi menjadi dua, teks primer (al-nass al-asliy) dan teks sekunder (al-nass altsanawiy). Teks primer adalah al-Qur'an dan teks sekunder adalah sunnah Nabi yang berperan sebagai komentar tentang teks primer. Sedangkan teks-teks keagamaan yang dihasilkan dari ijtihad-ijtihad para ulama, ahli fiqh, mufasir dianggap sebagai teks sekunder. ${ }^{9}$ Hal tersebut sebagai kontribusi untuk mengungkapkan kembali teks ayat al-Qur'an terkait Islam Wasthiyyah baik dalam memahami teks, Konteks, dan Kontekstualisasi dan bagaimana aplikasikan konsep Islam Wasthiyyah secara universal dan sebagainya.

\section{KONSEP ISLAM WASTHIYYAH DALAM AL-QUR'AN}

Jika ditinjau dari makna Islam Washatihiyyah dalam Al-Qur'an sebenarnya sudah memiliki beberapa arti baik secara bahasa dan istilah. Adapun secara bahasa Islam Wasthiyyah memiliki arti yang sangat mengandung beberapa spek yaitu pemimpin, tauladan, dan karena keduanya menjadi teladan, tumpuan pandangan, dan harapan anggota masyarakat dalam kehidupan. ${ }^{10}$ Sedangkan makna Wasat ditinjau dari Adapun kata wasat berarti posisi menengah di antara dua posisi yang berlawanan. Dapat juga dipahami sebagai segala yang baik dan terpuji sesuai dengan objeknya. Misalnya, keberanian adalah pertengahan antara sifat ceroboh dan takut kedermawanan adalah posisi menengah di antara boros dan kikir. Makna ini mengandung pengertian yang secara universal.

Perspektif Ali Syariati dalam bukunya Al-Ummah wa AlImamah menyebutkan keistimewaan kata ini dibandingkan kata semacam nation atau qabilah (suku). Pakar ini mendefinisikan kata

\footnotetext{
${ }^{9}$ Nashr Hamid Abu Zaid, Al-Imam al-Syafi wa Ta'sisu al-Idiyulujiyyah al-Wasatiyyah, (Beirut: Al-Markaz al-Tsaqafi al-'Arabi, 2007), h. 22.

${ }_{10}$ M. Quraish Shihab, Wawasan Al-Qur'an (Bandung:Mizan, 1998), h. 325 .
} 
umat dalam konteks sosiologis sebagai "himpunan manusiawi yang seluruh anggotanya bersama-sama menuju satu arah, bahu membahu, dan bergerak secara dinamis di bawah kepemimpinan bersama. ${ }^{11}$

Pendefinisian tersebut dapat memberikan suatu pintuuntuk kembali menganalisa dan mencari makna dalam berbagi macam literature tafsir terkait konsep Islam Wasthiyyah sesungguhnya, karena ummatan wasatan adalah umat moderat yang posisinya berada di tengah, agar dilihat oleh semua pihak dan dari segenap penjuru. Dengan menempatkan Islam sebagai posisi tengah agar tidak seperti umat yang hanyut oleh materialisme, tidak pula mengantarnya membumbung tinggi ke alam ruhani. Posisi tengah adalah memadukan aspek rohani dan jasmani, material dan spiritual dalam segala sikap dan aktivitas. ${ }^{12}$

\section{KAJIAN TEKS ISLAM WASTHIYYAH DALAM AL-QUR'AN}

Mencari konsep Islam Wasthiyyah yang sesungguhnya sebenarnya teks Al-Qur'an sudah menggariskan Q.S. Al-Baqarah ayat $143^{13}$. Namun demikiran, penafsiran dan makna Islam Wasthiyyah sampai saat ini masih tetap saja diperbincangkan dengan melahirkan makna yang berbeda. Adapun teks secara literlek berbunyi sebagai berikut:

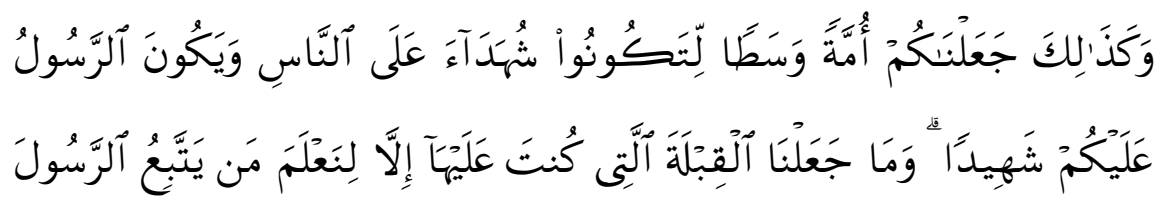

${ }^{11}$ M. Quraish Shihab, Wawasan Al-Qur'an (Bandung:Mizan, 1998), h. 328

12 Sabri Mide, Ummatan Wasatan Dalam Al-Qur'an (Kajian Tafsir Tahlili Dalam Q.S Al-Baqarah/2: 143), (Skripsi: UIN Makasar, 2014), h.11

13 Departemen Agama Republik Indonesia, Al-Qur'an dan Terjemahanya, ( Bandung: Diponegoro, 2010), h. 22 


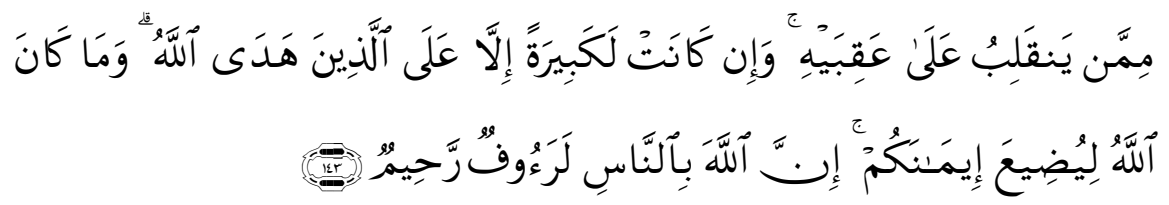

"Dan demikian (pula) Kami telah menjadikan kamu (umat Islam), umat yang adil dan pilihan agar kamu menjadi saksi atas (perbuatan) manusia dan agar Rasul (Muhammad) menjadi saksi atas (perbuatan) kamu. dan Kami tidak menetapkan kiblat yang menjadi kiblatmu (sekarang) melainkan agar Kami mengetahui (supaya nyata) siapa yang mengikuti Rasul dan siapa yang membelot. dan sungguh (pemindahan kiblat) itu terasa Amat berat, kecuali bagi orangorang yang telah diberi petunjuk oleh Allah; dan Allah tidak akan menyia-nyiakan imanmu. Sesungguhnya Allah Maha Pengasih lagi Maha Penyayang kepada manusia”.

Sekilas pengungkapan berbagai tafsir misalnya, Ibn Katsir menafsirkan makna ummatan wasathan dalam tafsirnya diartikan sebagai pilihan yang terbaik, supaya di hari kiamat nanti kalian menjadi para saksi atas umat-umat lainya, karena mereka semua mengakui keunggulan kalian, Quraisy adalah kabilah yang paling baik nasabnya Rasulullah Saw. sendiri adalah orang wasath' di antara kaumnya. Maknanya beliau adalah sosok paling mulia nasabnya. ${ }^{14}$ Ibn katsir melihat konsep Islam Wasthiyyah masih diungkapkan secara literlek yang didasarkan pada makna teksya belum pada makna konteks yang sesungguhnya maksud dari Islam Wasthiyyah tersebut.

Oleh karenya, menafsirkan masih di identik sebatas pengungkapan secara teks yaitu Islam Wasthiyyah berarti Islam yang adil. Konsep ini sebagaimana telah diriwayatkan Imam Ahmad sebagaimana Hadits Nabi Saw. berkata:

${ }^{14}$ Imam Ibn Katsir, Tafsir Al-Qur'an Al-adzim, (Jawa Tengah: Insan Kamil, 2015), h. 6. 
"Seorang Nabi datang diikuti oleh seorang laki-laki. Ada seorang nabi yang datang dan diikuti oleh dua orang atau lebih, lalu kaumnya dipanggil dan ditanya, apakah kamu sudah menyampaikan kepada kalian? "Mereka menjawab, "tidak." Maka Nabi tersebut dipanggil dan ditanya, "Apakah kamu sudah menyampaikan kepada kaummu? Ia menjawab, "Sudah." Ia ditanya, "Siapa saksinya? Ia menjawab, Muhammad dan umatnya. "Maka muhammad dan ummatnya dipanggil lalu ditanya, "Apakah Nabi ini sudah menyampaikan kepada kaumnya? "Mereka menjawab, "sudah" darimana kalian tahu? "Mereka menjawab, "Nabi kami datang kepada kami lalu mengabarkan kepada kami bahwa para rasul sudah menyampikan. Maka itulah firman Allah Swt, وكذا للك وسطا جعانكم امة dan demikian pula kami telah menjadikan kamu (umat

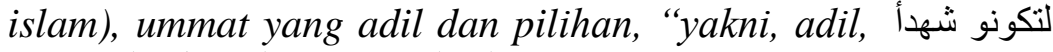
"Agar kamu menjadi saksi atas perbuatan manusia dan agar Rasul (muhammad) menjadi saksi atas (perbuatan) kamu. "Imam Ahmad juga meriwayatkan, dari Abu Sa 'id Al-Khudri. ${ }^{15}$

Tafsir Ath-Thabari memberikan penafsiran untuk menguatkan identis dan maksud Islam Wasthiyyah dalam Al-Qur'an didefinisikan sebagai "Hidup sedang-sedang Abu jafar mengatakan: Saya melihat bahwa kata al-wasthu dalam ayat tersebut bagian yang terletak diantara dua sisi, seperti وسط الدار (ruang tengah). Saya melihat bahwa Allah swt mengatakan jika umat ini adalah (ummah wasathah) karena mereka seimbang dengan agama ini, tidak berlebih-lebihan seperti orang-orang yahudi yang mengganti kitab Allah, membunuhi para Nabi Allah swt, mendustakan Allah dan mengingkari-Nya, tetapi mereka seimbang dan Allah mensifati umat ini dengan

${ }^{15}$ Shahih: HR. Ahmad (10684). Lihat selengkapnya, Shahih Jami’ AtTirmidzi (2961). 
(ummah wasata) karena perkara yang paling disukai oleh Allah adalah tengah-tengah (seimbang). ${ }^{16}$

Ada beberapa pendapat-pendapat para ulama yang diceritakan dalam bentuk riwayat tentang hakikat (al-wasthi') yang sesungguhnya, diantaranya sebagai berikut:

a. Salim bin Junadaan dan Ya'qub bin Ibrahim menceritakan kepada kami, katanya: Hafs bin Ghiyats menceritakan kepada kami, dari A'mash, dari Abi Shalih, dari Abi Sa'id dari Nabi Saw. tentang firman Allah Swt. وكذ للك جعانكم امة dan juga berarti keadilan ${ }^{17}$

b. Mujahid bin musa Muhammad bin Basysyar menceritakan kepada kami, katanya: Ja'far bin Aun menceritakan kepada kami, dari A'mash, dari Abi Shalih dari Abi Sa'id, dari Nabi Saw. dengan riwayat yang sama yang berarti keadilan. ${ }^{18}$

c. Muhammad bin Basysyar menceritakan kepada kami, katanya: Mu'ammal menceritakkan kepada kami katanya: sufyan menceritakkan kepada kami, dari A'masy dari Abi Shalih dari Said Al-Khudri, tentang firman Allah Swt امة yang berarti adil. ${ }^{19}$

d. Ali bin Isa menceritakan kepadaku, mengatakan : Sa'id bin sulaiman menceritakkan kepada kami, dari Hafs bin Ghiyats, dari Abi Shalih, dari Abu hurairah, dari Nabi Saw., tentang firman Allah Swt امة وسطا yang juga berarti Adil. $^{20}$

${ }^{16}$ Syaikh Ahmad Muhammad Syakir, Syaikh Mahmud Muhammad Syakir, Tafsir Ath-Thabari Surah Al-Baqarah, (MUI Jakrata: Pustaka Azzam, 2007), h. 602.

${ }^{17}$ Lihat Imam Tirmudzi dalam Tafsir Al-Qur'an (2961), Ibn Abi Hatim dalam tafsirnya (1/249).

${ }^{18}$ Lihat juga Imam Tirmidzi dalam Tafsir Al- Qur'an (2961), Ibn Abi Hatim dalam tafsirnya (1/249).

${ }^{19}$ Lihat juga, Ahmad dalam musnadnya (1/9).

${ }^{20}$ Lihat juga, Imam suyuthi dalam Ad-Duur Al-Mantsur (1/144). 
e. Abu kuraib menceritakkan kepada kami, katanya: Ibn Yaman menceritakkan kepada kami, dari Asy'ats, dari Ja'far,dari Sa'id, tentang firman Allah امة وسطا dan juga berarti Adil. ${ }^{21}$

f. Muhammad bin Sa'd menceritakkan kepadaku, katanya: Ayahku menceritakkan kepadaku, dari ayahnya dari Ibnu Abbas artinya kami menjadikan kalian ummat yang adil. ${ }^{22}$

Selain itu juga Abu Ja'far Menagatakan: kata شهداء adalah وكذا للك جعانكم امة وسط لتكو Fentuk dari jamak الثهيد Firman Allah Swt artinya, adil, agar kalian menjadi saksi bagi para nabi dan Rasul-Ku kepada Ummat manusia dengan menyampaikan bahwa umat ini telah menyampaikan perintah-Ku kepada umatnya, dan Rasul-Ku Muhammad Saw. sebagai saksi bagi kalian dengan beriman kepadanya dan wahyu yang diterima dari-ku sebagaimana dari beberapa riwayat yang lain. ${ }^{23}$

Abu Sa'ib menceritakkan kepadaku, katanya: Hafs menceritakkan kepada kami, dari A'mash, dari Abi Shalih, dari Ibnu Abi Sa'id, bahwasanya Rasulullah bersabda yang artinya: Nuh AS akan dipanggil pada hari kiamat kelak, kemudian beliau ditanya: "Apakah kamu telah menyampaikan risalah yang kau bawa?" beliau menjawab, ya" kemudian umat Nuh AS pun umatnya menjawab, "Tidak pernah ada orang yang yang membawa peringatan yang datang kepada kami. "Maka beliau ditanya lagi, "Lantas siapa yang mengetahui hal itu?" Nuh AS menjawab, "Muhammad dan umatnya. “Maka itulah ynag dimaksud firman Allah. "Dan demikian (pula) kami menjadikan kamu (umat Islam), umat yang adil dan pilihan agar

${ }^{21}$ Baca Selengkapnya. Mujahid dalam Tafsirnya, h. 215

${ }^{22}$ Baca juga Imam Suyuthi dalam Ad-Dur Al Mantsur, (1/459).

${ }^{23}$ Syaikh Ahmad Muhammad Syakir, Syaikh Mahmud Muhammad Syakir, Tafsir Ath-Thabari Surah Al-Baqarah, (MUI Jakrata: Pustaka Azzam, 2007), h. 604.. 
kamu menjadi saksi atas (perbuatan) manusia dan agar Rasul (Muhammad) menjadi saksi atas perbuatan kamu. ${ }^{24}$

KONTEKS DAN KONTEKSTUALISASI ISLAM WASTHIYYAH PERSPEKTIF TAFSIR DAN PEMIKIRAN ISLAM

Penafsiran Islam Wasathiyyah di era modern-kontemporer semakin meluas dan berkembang seiring dengan munculnya berbagai problematika dan aksi tindakan-tindakan dan aliran Islam yang semakin maraknya di perbincangkan. Sehingga beberapa tafsir kontemporer dan pemikiran Islam memberikan Makna Islam Wasthiyyah bukan pada zaman hidup di masa lampau melainkan Islam Wasthiyyah merupakan Islam yang menagndung berbagai aspek-aspek keislaman yang bersifat universal bukan dilihata sebatas teks yakni berarti adil. Hal ini dalam pengungkapan

M. Quraish Shihab bahwa, Islam Wasthiyyah memiliki karakteristik masyarakat yang moderat yakni tidak tenggelam dalam kehidupan materialism (pertengahan), tidak juga membumbung tinggi dalam kehidupan spiritualisme. Ketika pandangan mengarah ke langit, kaki harus tetap berpijak di bumi. Adapun posisi pertengahan menjadikan manusia tidak memihak ke kiri dan ke kanan, suatu hal di mana dapat mengantar manusia berlaku adil. Posisi pertengahan menjadikan seorang dapat dilihat oleh siapa pun dalam penjuru yang berbeda, dan ketika itu ia dapat menjadi teladan bagi semua pihak. Posisi itu juga menjadikannya dapat menyaksikan siapa pun dan dimana pun. Allah swt menjadikan umat Islam pada posisi pertengahan agar kamu dapat menjadi saksi atas perbuatan manusia yakni umat yang lain, tetapi ini tidak dapat kalian lakukan kecuali jika kalian menjadikan Rasul. ${ }^{25}$

${ }^{24}$ Lihat Imam Al-Bukhari dalam Kitab bab Al-I'tisham (7349).

${ }^{25}$ M.Qurais Shihab, Tafsir Al-Misbah, Pesan, Kesan, dan Keserasian alQur'an,, (Jakarta: Lentera Hati, Cet.1.2017), h.415. 
Penafsiran tersebut sebada dengan M.Thalibi (pemikiran tafsir kontemporer) ketika menafsirkan dan menyimpulkan "umat alwasthi" berdasarkan pendapat-pendapat ulama terdahulu yang termuat dalam bukunya bahwa ummat al-wasath tidak berbicara mengenai waktu, umat al wasath dalam ciri khas karakteristik adalah umat yang selalu berlaku adil dan bersikap pertengahan tidak memihak antara satu dengan yang lainya, bersikap bijaksana, selalu menjalankan syariat Islam dapat dikatakan melalui jalan yang lurus. ${ }^{26}$

Selain merujuk kepada pendapat-pendapat para ulama, M.Thalibi dalam menafsirkan ummat al-wasthi' mengaitkan ayat yang satu dengan ayat lain kemudian membandingkan sehingga dalam perspektifnya, Ummat al-wasthi' dapat dideskripsikan secara universal dalam arti bukan berlaku adil akan tetapi juga bermakana menyaksikan bahwa tiada tuhan selain Allah Swt., percaya kepada Allah swt dan Nabi, serta mengikuti perintah Allah swt dan menjauhkan segala laranganya dengan kata lain menuju jalan yang lurus. ${ }^{27}$

Menelaah lebih jauh dan hasil secara signifikan agar bisa dipetakkan konteksluasi, penulis akan melakukan dan menelaah makna dan konsep Islam Wastiyyah dalam al-Qur'an. Lebih-lebih yang paling urgen adalah bagaimana karakteristik atau kontekstualisasi Islam Wasthiyyah dalam Al-Qur'an diantara beberapa pengungkapan tafsir era klasik hingga kontemporer. Maka ada beberapa sikap yang dimiliki Islam Wasatiyyah, diantaranya sebagai berikut.

a. Ihsan yaitu berbuat kebajikan. Setengah dari padanya ialah mencintai kaum kerabat dan tetangga dan menajuhkan dari pertengkaran. Selain itu juga ihsan dalam konteks mendorong

${ }^{26}$ M. Thalibi, Ummat Al-Wasthi (Islam Watahaddiyat AL-Ma'asirah), (Sarashi Linnasir: Ceres Edition,1999,) h.24.

27 M. Thalibi, Ummat Al-Wasthi (Islam Watahaddiyat AL-Ma'asirah), h. 30 
orang untuk berbuat jasa, bersusah payah untuk kebahagiaan kerabat, anak, istri, dan masyarakat sosial. Dalam konteks inilah Islam Wasthiyyah dapat di nilai secara actual dan empiris. ${ }^{28}$

b. Keadilan yaitu Tujuan Allah Swt. menjadikan umat slam sebagai ummatan wasathan adalah agar menjadi saksi atas (perbuatan manusia). Salah satu syarat menjadi saksi yaitu adil. Saksi yang adil tidaklah mementingkan kepentingan suatu individu atau kelompok. Ia akan bertindak sesuai dengan takarannya. Sesuai dengan penjelasan sebelumnya, kita harus menilainya dari segala sisi, sehingga kita bisa berlaku adil terhadap apapun dan siapa pun. Adil juga bukanlah sama rata, melainkan mengembalikan sesuatu pada tempatnya.

Setelah berusaha untuk berlaku adil, kita harus bisa mengontrol terhadap apapun yang terjadi. Diisyaratkan dari potongan ayat diatas bahwa kita akan menjadi saksi atas perbuatan manusia ummat yang lain yaitu saksi yang aktif untuk menyebarkan nilai-nilai keadilan. Tetapi, hal tersebut tidak dapat dilakukan kecuali jika kita menjadikan Nabi Muhammad Saw. sebagai saksi atas perbuatan kita. Lalu, bagaimana Nabi Muhammad Saw. menjadi saksi jika beliau sudah tidak ada di dunia ini. Nabi Muhammad Saw. masih bisa menjadi saksi atas perbuatan kita pada zaman sekarang yaitu dengan menjadikannya sebagai teladan dalam kehidupan kita. Hamka menjelaskan bahwa, Islam Wasathiyyah harus mampu melakukan keadilan dalam konteks membela kemanusiaan, mencintai tanah air, menjaga

${ }^{28}$ Hamka, Lembga Hidup (Ikhtiar Sepenuh Hati Memenuhi Ragam Kewajiban Untuk Hidup Sesuai Ketetapan Ilahi), (Jakarta: Republika Penerbit, 2015), h 201 
budi pekerti, dermawan, dan menjaga hak persamaan saudara. ${ }^{29}$

c. Intropeksi (Muhasabah) yaitu memeriksa dan menimbang diri sendiri seberapa baik dan seberapa buruk di masa lalu dan apay yang telah diperbuat untuk hari esok. Secara spesipik ada tiga hal sebagai sebuah pencapaian dalam muhasabah sebagai umat, diantaranya, 1) Perlu memiliki cahaya hikmah artinya pengetahuan untuk membedakan kebaikan dari keburukan. 2) Mencurigai diri sendiri untuk melihat kelemahan diri secara obyektif, dan 3) kemampuan membedakan nikmat dan ujian. ${ }^{30}$

Melihat sekilas kontekstualisasi atau karakteristik Islam Wasatiyyah dalam al-Qur'an. secara garis besar adalah sebagai mahluk bermasyarakat dan menjauhkan dari segala kekerasan dan menjauhkan dari segala yang merugikan sesame. Walaupun menguntungkan diri sendiri seorang. Dan mencapai yang muslihat bagi bersama. Contohnya sebagai berikut:

1. Ingin supaya sesama manusia memperoleh kebaikan.

2. Pindah "rasa" kepada "kerja". Artinya bukan hati saja yang cinta, tetapi diikuti dengan perbuatan. Itulah yang menimbulkan amal kerja sosial dan lain sebagainya.

3. Ikhlas merasa senang melihat kemenangan yang dicapai oleh sesame manusia karena usahanya.

4. Memberi ma.af kesalahan temandan sudi menahan cerca dan makian. Tidak berdendam dan melepaskan nafssu sakit

29 Hamka, Falsafah Hidup, Memecahkan Rahasia Kehidupan Berdasarkan Al-Qur'an dan As-Sunnah, (Jakarta: Republika Penerbit, 2015), h.317

30 Zainal Aridin, Tafsir Ayat-Ayat Manajemen, (Yogyakarta: Program Studi Manajemen Pendidikan Islam Fakultas Ilmu Tarbiyah dan Keguruan UIN Sunan Kalijaga, 2018), h. 173 
hati, karena seorang pendendam biasanya terlepas dari ikatan masyarakat dan hidup terpencil. ${ }^{31}$

Menurut Ajaran Islam bahwa, konteks Islam Wasatiyyah pada hakikatnya terletak pada konsep yang telah dijabarkan baik dalam konteks tafsir dan kontekstualisasi yang disatukan sebagai ajaran tauhid yaitu mengakui keesaan Allah swt dan tidak ada perbedaan warna kulit atau ras diskriminasi. Tidak ada perbedaan karena perlainan keturunan tapi melainkan hak manusia sama dan kewajibanya pus sama bertakwa kepada Allah Swt. Al-Qur'an telah memberikan garis terhadap berbagai pemahan terhadap konsep ajaran yang salah satu yang diinginkan al-Qur'an adalah Islam Wasthiyyah bermakna adil, toleransi dan menjalankan hukum-hukum Allah Swt dengan adil ditinjau dari segi berbagai macam aspek kehidupan. ${ }^{32}$

\section{(Diagram Karakteristik dan Nilai-Nilai Islam Wasathiyyah)}

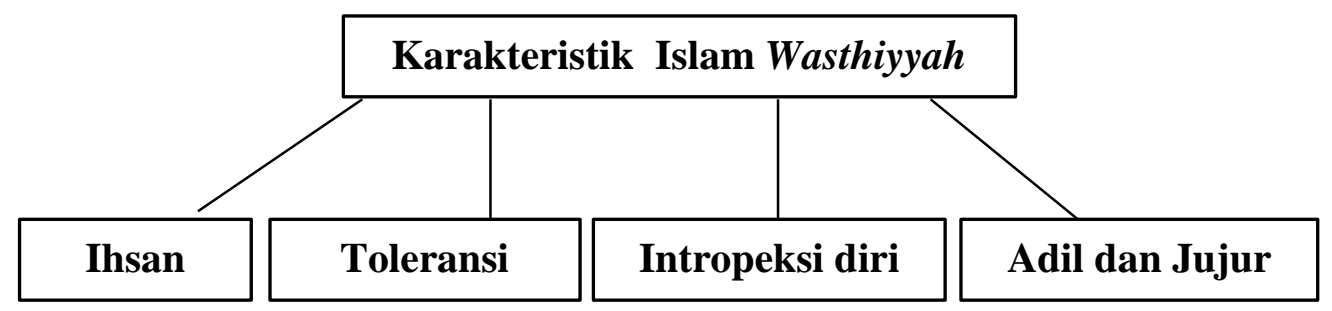

Jika ditinjau dari beberapa aspek penafsiran baik dari segi teks, konteks, dan kontekstualisasi dalam konteks kekinian bahwa, konsep utama yang dimiliki Islam Wasthiyyah pada dasarnya adalah

31 M.Thalibi, Ummat Al-Wasthi (Islam Watahddiyat AL-Ma'asirah), h. 30

${ }^{31}$ Hamka, Lembga Hidup (Ikhtiar Sepenuh Hati Memenuhi Ragam Kewajiban Untuk Hidup Sesuai Ketetapan Ilahi), 202-203

32 Hamka, Falsafah Hidup, "Memecahkan Rahasia Kehidupan Berdasarkan Al-Qur'an dan As-Sunnah”, (Jakarta: Republika Penerbit, 2015), h.343 
mengaktualisasikan nilai-nilai kenaikan baik cakupanya terhadap Negara, misalkan pemimpin, maupn dalam konteks segi kehidupan secara universal. Islam wasthiyyah dalam beberapa penafsiran bukan hanya sebatas adil, melainkan dalam hubungan persaudaraan dapat menjalin hubungan dengan baik dalam arti tidak bersifat liberal, ekstrim, dan menebarkan berbagai informasi yang membuat berbagai problematika sehingga terjadi perselisishan diantara ummat tersebut.

Dalam Islam, ajaran tentang toleransi bisa diaplikasikan lewat beberapa cara, di antaranya: Pertama, berpegang pada prinsip kalimatun Saw.a' (commom platform) untuk pergaulan antar umat beragama dan berbagai kepentingan masyarakat yang plural. Titik persamaan ini terletak pada kebutuhan untuk mencintai Tuhan, mencintai makhluk Tuhan, dan mengakui suara hati nurani. Kedua, menumbuhkan pemahaman keagamaan yang integratif, egaliter, inklusif, dan plural dengan melakukan penguatan metodologi terhadap kajian-kajian Islam, semisal pengembangan metode takwil (hermeneutik), serta pentingnya mendefinisikan ulang tentang diri dan orang lain. Termasuk mengkaji konsep-konsep yang selama ini dianggap telah baku, seperti konsep mukmin/kafir, muslim/munafik dan lain-lain.

Ketiga, mentradisikan musyawarah dan berdiskusi. Tradisi musyawarah ini akan menumbuhkan sikap toleran dan mengakui keberagaman pemikiran dan sikap setiap insan dalam mencari hal yang baik dan benar. Kebaikan dan kebenaran bisa datang dari manapun, termasuk dari orang yang dibenci sekalipun. Untuk itu, pemahaman keagamaan harus dibangun secara inklusif dan tidak mengedepankan klaim. Klaim kebenaran dari suatu kelompok dengan menafikan kebenaran dari kelompok lain hanya akan menimbulkan kecurigaan dan pertentangan. Keempat, jaminan terhadap terpenuhinya lima hak dasar manusia, yakni: (1) hifdz aldin, menjamin keyakinan agama masing-masing; (2) hifdz al-nafs, jaminan terhadap keselamatan jiwa setiap warga masyarakat; (3) 
hifdz al-aql, menjamin setiap bentuk kreasi pikiran, baik bersifat intelektual maupun budaya dan seni; (4) hifdz al-nasl, menjamin keselamatan keturunan dan keluarga dengan menampilkan moral yang kuat; dan (5) hifdz al-mal, menjamin keselamatan harta benda dan hak kepemilikan36. Konsep dasar ini harus ditanamkan sejak dini pada anak untuk dapat bersikap toleran kepada agama oranglain dan mengajarkan agama secara integral-komprehensif dari berbagai sudut pandang. Pentingnya persatuan dan kesatuan bangsa sebagai alat pemersatu dalam memberantas terorisme. ${ }^{33}$

Menurut Yusril Ihza Mahendra, perbedaan pendapat dalam mensinergikan antara Islam dan modernitas dikalangan modernis dan fundamentalis Islam merupakan akibat dari kecenderungan penafsiran dalam memahami doktrin agama yaitu Al-Quran dan Sunnah Nabi yang dijadikan acuan dalam membangun tatanan masyarakat. Dijelaskan bahwa "keduanya (modernism dan fundamentalisme Islam) sama-sama berdasarkan kepada Al-Quran dan Sunnah Nabi. Dan bertujuan untuk membangun suatu tatanan masyarakat Islam, sesuai dengan maksud doktrin yang termaktub dalam Al-Quran dan Sunnah Nabi itu. Pada modernis Islam cenderung menafsirkannya secara elastik dan fleksibel. Sementara para fundamentalis cenderung menafsirkannya secara rigid dan literalis. ${ }^{34}$

Dengan demikian, dalam beberapa literatur tafsir menyebutkan bahwa, kontektualisasi penafsiran ummatan wasatan (Islam Wasthiyyah) dapat berarti kebaikakan bahkan diaktualisasikan secara universal dalam konteks kehidupan dan bernegara. Baik menjaga nama baik, berjihad dalam Islam, dan menebarkan keadilan

${ }^{33}$ Buddy Munawar Rahman, Kontekstualisasi Doktrin Islam dalam Sejarah, Jakarta: Paramadina. 1994. h. 546-549.

${ }^{34}$ Yusril Ihza Mahendra, Modernisme dan Fundamentalisme Dalam Politik Islam, Jakarta: Paramadina, 1999, h.29. 
sebagaimana Nabi Muhammad Saw. menebarkan kebenaran di muka bumi ini tanpa adanya pertengkaran dan kekerasan.

\section{KESIMPULAN}

Pada kesimpulan ini, secara spesifik prinsip-prinsip yang dimilki oleh ummat wasathiyyah adalah: Pertama, prinsip tidak melampaui batas (ghuluww), baik dalam bersikap, bertutur kata, berbuat, termasuk beribadah. Kedua, prinsip tidak melakukan hal-hal yang sia-sia belaka, baik perkataan maupun perbuatan. Ketiga, prinsip selalu berada dalam al-Shirath al-Mustaqim (jalan yang lurus dan benar). Artinya, ummatan wasathan dituntut untuk selalu berada dalam petunjuk jalan lurus dan benar (Islam) dengan senantiasa mentaati syari'atnya, mengikuti Al-Qur'an dan as-sunnah. Selain itu juga ummat al-wasath dapat dikatakan sebagai jalan lurus dan benar merupakan puncak moderasi karena berada di jalan yang benar berarti berada di tengah-tengah kebenaran, tidak menyimpang, dan tidak pula ekstrim. Selain itu, Mekkah, tempat lahirnya Islam, terbukti berada di tengah, titik tengah bumi. Islam itu bukan agama liberal, bukan juga sekuler, dan tidak juga ekstrim.

\section{DAFTAR PUSTAKA}

Geovani, Jeffrie,. Civil Religion Dimensi Sosial Politik Islam", Jakarta: Gramedia Pustaka Utama, 2013.

Mustaqim, Abdul., Metode Penelitian Al-Qur'an dan Tafsir, Yogyakarta: Idea Press, 2015.

Rahmat, Jalaludin., Islam Aktual, Bandung: Mizan, Cet. X, 1998.

Ahmad, Kamaruzzaman Bustaman., Islam Historis (Dinamika Studi Islam di Indonesia), Yogyakarta: Galang Press, 2002.

Pawenang, Supawi., Islam Perspektif Manajemen, Yogyakarta: Idea Press, 2010. 
Madjid, Nurcholis., Khazanah Intlektual Islam, Jakarta: P.T. Bulan Bintang, 1994.

Thontawi, Jawahir,. Islam, Politik, dan Hukum Esai-esai Imiah untuk Pembaharuan" Yogyakarta: Madyan Prres, 2002.

Mahfudz, Sahal., Nuansa Fikih Sosial, Yogyakarta: LKiS, 1994.

Rahman, Fazlur., Islam, Chicago: The University of Chicago Press, 1979.

Abu Zaid, Nashr Hamid., Al-Imam al-Syafi wa Ta'sisu alIdiyulujiyyah al-Wasatiyyah, Beirut: Al-Markaz al-Tsaqafi al-'Arabi, 2007.

Shihab, M. Quraisy., Wawasan Al-Qur'an, Bandung: Mizan, 1998.

----------------., Tafsir Al-Misbah (Pesan, Kesan, dan Keserasian al-Qur'an), Jakarta: Lentera Hati, Cet.1.2017.

Sabri Mide, Ummatan Wasatan Dalam Al-Qur'an (Kajian Tafsir Tahlili Dalam Q.S Al-Baqarah/2: 143), (Skripsi: UIN Makasar, 2014

Ilham Muchtar, "Ummatan Wasathan Dalam Perspektif Tafsir AlTabariy, Jurnal: Vol. 2, No. 2, Juli-Des', 2013.

Departemen Agama Republik Indonesia, Al-Qur'an dan Terjemahanya, Bandung: Diponegoro, 2010.

Ibn Katsir, Imam,. Tafsir Al-Qur'an Al-adzim, Jawa Tengah: Insan Kamil, 2015.

Muhammad Syakir, Syaikh Ahmad, Syaikh Mahmud Muhammad Syakir, Tafsir Ath-Thabari Surah Al-Baqarah, (MUI Jakrata: Pustaka Azzam, 2007.

M.Thalibi, Ummat Al-Wasthi (Islam Watahddiyat AL-Ma'asirah), (Sarashi Linnasir: Ceres Edition,1999,) 
Hamka, Falsafah Hidup, Memecahkan Rahasia Kehidupan Berdasarkan Al-Qur'an dan As-Sunnah, Jakarta: Republika Penerbit, 2015.

Hamka, Lembga Hidup (Ikhtiar Sepenuh Hati Memenuhi Ragam Kewajiban Untuk Hidup Sesuai Ketetapan Ilahi), Jakarta: Republika Penerbit, 2015.

Aridin, Zainal., Tafsir Ayat-Ayat Manajemen, (Yogyakarta: Program Studi Manajemen Pendidikan Islam Fakultas Ilmu Tarbiyah dan Keguruan UIN Sunan Kalijaga, 2018.

Rahman, Buddy Munawar, Kontekstualisasi Doktrin Islam dalam Sejarah, Jakarta: Paramadina. 1994.

Mahendra, Yusril Ihza, Modernisme dan Fundamentalisme Dalam Politik Islam, Jakarta: Paramadina, 1999. 